finally - for this could go on and on-the devotion to adult education and the readiness for hard work and democratic giveand-take demonstrated by the conference participants.

\title{
Experiments in the Education of Older Adults*
}

\section{Wilma Donahue}

Chairman, Division of Gerontology, Institute for Human Adjustment, University of Michigan

$\mathbf{T}$

HERE IS a widespread acceptance of the belief that older people are unable to understand new ideas, to acquire new information, or to adopt new methods of learning or of solving problems. Results of psychological studies have tended to document these assumptions. They have shown that, while there are wide individual differences, the overall pattern of age change is one of decline. When older men are compared with younger men of like professions, they make lower test scores, on an average, than their younger colleagues. ${ }^{1}$ Some abilities have been found to decline before others. For example, capacity to form comparisons and to reason by analogy declines progressively throughout the adult years, but ability to recall information remains fairly constant throughout the three decades after thirty. ${ }^{2}$

Such objective data are perhaps responsible, in large part, for the attitude that any endeavor aimed at the education of the older adult would be fruitless. At the same time, the implications for education of the increases in average longevity and the larger number of individuals living to be old have not yet been sufficiently appreciated to lead to the provision of educational opportunities for the aging. To be sure, older individuals have been welcome and

*Delivered at the Section II Symposium on "Education for Middle Age and Later Maturity", Second International Gerontological Congress, St. Louis, Missouri, September 13, 1951.

${ }^{1} \mathrm{~K}$. Sward. Age and mental ability in superior men. Am. J. Psychol., 58, $1945,443-479$.

G. Foulds and J. Raven. Normal changes in the mental abilities of adults as age advances. J. Ment. Sci., 94, 1948, 133-142. 
many have been enrolled in adult education courses, but there has been little attempt on the part of educators to evaluate course content and instructional method with reference to meeting the changing needs of aging individuals.

It has been our assumption, based upon evidence of the effect of use upon the maintenance of an ability at a high level of efficiency, e.g. vocabulary, ${ }^{3}$ that the use of any psychological function will retard its aging. As a corollary, we have also assumed that exercise of an ability which has already declined can restore its function. Moreover, it appeared reasonable to predict that as aging people realized the need to prepare for useful living in their later years they would become motivated to learn about the changes which come with age and how to make adjustments to them. ${ }^{4}$ Therefore, the Division of Gerontology of the Institute for Human Adjustment, in cooperation with the Extension Service of the University of Michigan, undertook to experiment with various types of educational programs which would test these hypotheses.

\section{The First Course}

The first University of Michigan course on adjustment to aging was offered in the spring of 1948. It has already been reported in some detail. 5 Topics selected for consideration were based upon an earlier investigation of the expressed needs and problems of older people. Lecturers were drawn from the University faculty. The class met for weekly two-hour sessions over a period of 12 weeks. Since it was a noncredit course, enrollment was open to all interested persons.

The students were given an opportunity to make a written evaluation of the course. In general, their reactions were favorable, and they recommended that the course be continued. Lectures which they identified as having the most value were selected in the following order: psychological aspects of aging; biology of aging; mental health; physical health; and living arrangements. The least helpful lectures were judged to be those dealing with creative activities, such as gardening, silverwork, recreation and cultural pursuits. The reasons given most fre-

${ }^{\circ}$ Charlotte Fox. Vocabulary ability in later maturity. J. Educ. Psychol., $38,1947,482-492$.

"Wilma Donahue. "Age with a Future", in Social Work in the Current Scene. New York: Columbia University Press, 1950. 71-86.

${ }^{\circ}$ Clark Tibbitts. Aging and living. Adult Educ. Bull., 13, 1948, 204-211. See also W. Donahue, "Age with a Future", op. cit. 
quently for liking the course were that it provided a basis for dealing constructively with the personal problems related to aging, and that it renewed faith in the older person's ability to do something. An expressed criticism of the course was that there was not enough discussion. An analysis of the reasons given for failure to enter into discussion, however, indicates that lack of discussion stemmed from a great diffidence on the part of the students to express themselves before a group, rather than from an absence of opportunity.

\section{Subsequent Courses}

The increasing interest in the problems of aging and the recognition that adult education can assist in helping individuals prepare for the latter phase of life have resulted in requests from many communities for courses on old age. The University has therefore continued to offer courses patterned after its first one. Enrollment has never been limited to old people. On the contrary, the classes in the various communities have included individuals ranging in age from the late teens to the eighties, with a mean age of sixty-one. Educational background has ranged from fourth grade through several years of graduate work. Occupational groups have always run the gamut from unskilled workers to the professional levels. Reasons given most frequently for enrolling in the course have been "to escape loneliness", "to obtain help with personal problems", and "to gain information about old people for professional reasons". ${ }^{6}$

Of particular interest have been some of the outcomes of the courses expressed in activities of the individual class members. In one instance, even before the course was completed, an elderly librarian in the class had organized a similar course in her branch library and was using other class members to give the lectures, a lawyer presenting the lecture on legal problems, a personnel manager discussing the problems of employment, and so forth. This program has been continued and other branch libraries have initiated similar programs. Another 66-year-old student in the same class designed a program for grandparents which the local school board allowed her to offer in the adult education curriculum. In some of the classes, the students have organized into clubs which continue to meet for educational and recreational

${ }^{\circ}$ Wilma Donahue. Preparation for living in the later years. Adult Education, 1, 1950, 43-51. 
purposes after the completion of the course. ${ }^{7}$

These and other activities initiated by the students as a result of their course experience gave evidence of the ability and interest of older people in working toward the solution of their own problems. It seemed therefore that a somewhat more dynamic approach to the study of aging and its personal and social significance could be undertaken by the students enrolled in the courses on aging. In order to obtain the responses and explore the capabilities of older people in a class conducted along workshop lines, a new type of course was offered. Enrollment was kept small (12 people) so that ample time would be available for individual and group consultation with the instructor. At the first meeting, the nature of the course was explained. It was pointed out that formal lectures would not be presented, that the class would divide into small groups, and that each group would design and execute a project. The first task of the total class was to identify what it considered to be the most important problems confronting older people. Following this, the class divided into three smaller groups, each of which held a discussion and selected a topic to investigate as its course project. The groups reassembled and reported their topics and the reasons for selecting them. A few changes in the membership of the groups took place, since each student was encouraged to work on the project which appealed to him most. One student withdrew from the class because she said she did not care to work; she had expected something "more entertaining".

The three topics selected for investigation were the following: the satisfactions and dissatisfactions of older people with the church; the employment and training opportunities for older women in the local community; and a plan for establishing a community center for older people.

After the first general meeting of the class, each of the project groups met with the instructor once a week, and as many times individually as they wished. The class met once a month as a whole to hear progress reports from the groups and to obtain a mutual evaluation of their work.

The methods followed by each group were similar. As an illustration, I shall describe briefly the work of the students who

'W. Hunter, D. Coons and C. Tibbitts. "A Recreational-Educational Experiment", in Planning the Older Years (edited by W. Donahue and C. Tibbitts). Ann Arbor: University of Michigan Press, 1950. 119-140. 
elected to study employment and training opportunities for older women. At their first group meeting, they decided to prepare for illustrative purposes the type of brochure on employment and training which a community might issue for its older women. Employment was defined to mean remunerated work, and the training opportunities to be considered were restricted to those available at the local level offering preparation for jobs open to older women. The group outlined the various sections which should be included in the brochure, and individual members assumed responsibility for developing the content of the sections. For example, one woman volunteered to prepare the first and second sections, devoted respectively to the problem of employment and training for older women and the problem of how to get a job. She also prepared a bibliography of references for further reading which should be included in the final section of the brochure. The other two members of the group carried out the investigation of job and training opportunities. Their first task was that of designing schedules on training and employment opportunities, which they used subsequently in interviewing local employers and employment agencies. Some of the types of employment they studied were "Kiddie Kare", practical nursing, nurse's aide work, office work, and housekeeping service. Information and data, including costs of training, salary, average income, job specifications, special health qualifications, age limitations, etc., were recorded for systematic presentation in the brochure. The class was not of long enough duration to permit study of an exhaustive list of occupations, but the students became so motivated in their work that they are continuing the project and hope to interest the community in completing the brochure through one of its regular agencies.

The other groups made an equally dynamic approach to the problems which they investigated. $^{8}$ In each group, the oldest members (75-80 years) were the most active, in spite of the fact that none of them could drive an automobile and public transportation was not readily available.

There is no reason why such projects as were carried out by this class might not be executed just as effectively in the program of golden-age groups. In fact, it is to be recommended that such groups develop goals

"W. Donahue. "Challenges of Longer Living", in Proceedings of the 1951 North Carolina Conference on Aging (in press). 
on a broader base than recreation, around which most of them are now organized. In every community there are people who rebel at the notion of old age as a time of continuous play and who refuse to participate in the recreational programs of the usual golden-age club, but who nevertheless crave and need the companionship of their peers. For these persons, projects designed to study the problems of their own age group are not only acceptable as educational activities, but they also provide an opportunity to function as members of a social group and can be used to stimulate community action.

\section{A New Course}

In further recognition of the fact that older people have too few opportunities for social experience and lack information and preparation for meeting the problems of aging, we have designed a course to be presented for the first time this fall which will attempt to meet both of these needs.

It will combine educational experience with social and recreational activities to provide knowledge and practice in the art of mature living. The first hour of the class, which will convene at 5:30 P.M., will be devoted to a discussion of such topics as health, nutrition, psy- chological change, mental hygiene, financing the later years, employment opportunities and retirement. Following the discussion, the group will have an evening lunch together, after which an hour will be devoted to practice in social living. The latter portion of the class meetings will present an opportunity for making friends, provide a "feeling" of belonging to a social group, encourage participation and practice in group activity, illustrate the value of service to others, and stimulate planning for social living in the later years. The social-recreational activities will include games, group singing, square dancing, instrumental music, dramatics, hobby shows, and a party. These activities will be carried out by the students, but, at the same time, they will be studied with reference to their meaning in the total pattern of living and thus will be of an instructional nature. Evaluation procedures will be a part of both phases of the course. The course will be presented this fall to a group made up entirely of workers from one industrial plant as a part of that industry's preretirement program. It will also be offered in another community as a regular Extension Service course, although certain industries, churches, and old-age clubs are planning to enroll rep- 
resentative groups. A report on the outcomes of these experiments will be made upon their completion.

\section{A TV Course}

Interesting as classroom programs for older people may be to the educator, he cannot escape a feeling that the task of training the aging population in an understanding of the potentialities of the later years is of too gigantic a proportion to be dealt with on such an individual basis. Moreover, not only must the aging individual recognize his problems and resources, but society as a whole must change its attitudes toward the aging. The increased numbers of documentary films and radio and TV programs on these topics are evidence of a growing interest and concern on the part of large segments of the population.

The University of Michigan, in conjunction with station WWJ-TV in Detroit, has carried out the unique experiment of offering a series of courses by television. One of the telecourses presented was called "Living in the Later Years: Hobbies Put to Work". The student, or "viewdent", enrolled in the sevenweek course through the University Extension Service by paying a fee of one dollar. Each week the student received supplementary printed materials and reading lists prepared by the instructor, and at the end of the course took an examination and received a certificate of participation. Obviously anyone could participate without registration in the visual aspects of the course, and a study made by the TV station indicated a viewing audience of approximately 100,000 .

Each of the weekly telecourse meetings was twenty minutes in length. During each class period one or more older people demonstrated their hobbies and discussed with the instructor how and at what age they had begun the hobbies, what satisfactions they derived from them, what costs were involved in learning and practicing them, etc. A faculty guest expert also appeared on each telecast and briefly related the pursuit of the hobbies demonstrated to some of the broader goals of living. The hobbies which were demonstrated included bookbinding, sculpture, pottery-making, cakedecorating, spice-blending, gardening, weaving, aluminumetching, stenciling and other crafts for shut-ins, gem-cutting, wood-working, toy crafts, painting, silversmithing, and music.

The purpose of the series was to illustrate the need and ability of older people to continue in a responsible social role. The theme "putting hobbies to work" 
was expressed by showing the ability of older people to make a craft or talent contribute to financial independence, bring satisfaction through service to other people, and provide the pleasure of creative experience. Every effort was made to present the older person in the dignified role which he or she had achieved in earlier life and to avoid the caricature and sentimentality so frequently encountered in programs dealing with older people.

A total of 252 students enrolled in the course, 138 women and 114 men. An optional questionnaire distributed with the
15 to 68 ; the mean age was 45 for both men and women. Educational background ranged from third grade through graduate school; 68 per cent were high school graduates, and 24 per cent had completed college. A classification of occupations appears in the following table.

Ninety-four of the students returning questionnaires owned television sets; length of time the sets had been owned varied from six months to four years, and average length of ownership was one and a quarter years. These figures seem to indicate that there may be no significant relationship between

\begin{tabular}{|lcc|}
\hline \multicolumn{3}{|c|}{ Table 1 } \\
Occupational Classification of Students \\
\hline \multicolumn{1}{|c|}{ Classification } & Number & Per Cent \\
\hline Professional and managerial & 31 & 32 \\
Clerical and sales & 18 & 19 \\
Service & 3 & 3 \\
Agricultural & 1 & 1 \\
Skilled & 6 & 6 \\
Semi-skilled & 1 & 1 \\
Unskilled & 1 & 1 \\
Housewives & 33 & 34 \\
Students & 2 & 2 \\
\hline
\end{tabular}

final examination was returned by 96 students, 58 women and 38 men. On the basis of the responses to the questionnaires, we can report upon some characteristics of the students and their reactions to the telecourse.

The students returning questionnaires ranged in age from length of television set ownership and interest in educational TV programs. Fifty-one per cent of the students attended all seven class meetings, and another 21 per cent attended six sessions. Only 13 per cent of the group viewed less than five of the programs. 
Most of the students (83 per cent) had one or more hobbies. Table 2 shows the percentage of men and women in two age categories who reported one or more hobbies.

\begin{tabular}{|ccc|}
\hline \multicolumn{3}{|c|}{$\begin{array}{c}\text { Table 2 } \\
\text { Percentage of Students with } \\
\text { One or More Hobbies } \\
\text { by Sex and Age }\end{array}$} \\
\hline \multicolumn{3}{|c|}{ Age Group } \\
\cline { 2 - 3 } Sex & $30-49$ & $50-69$ \\
Male & 95 & 80 \\
Female & 76 & 89 \\
Both & 82 & 85 \\
\hline
\end{tabular}

A comparison of the number of hobbies of the men in the 3049-year-old age group with those in the 50-69-year-old group shows that only 5 per cent of the younger men had no hobbies, while this was true of 20 per cent of the men in the older group. A reverse relationship was found in the women's groups. Of the younger women, 24 per cent had no hobbies, while only 11 per cent of the older group were without hobbies.

In response to the question, "What was the one most important thing you learned from the course?", we found that each of the answers could be classified under one of the following seven categories:

Understanding old age and its problems
Importance of preparation for activities in later life

Rewards of hobbies in the later years

Old age can be a time of happiness and usefulness

Personal inspiration with reference to aging

Old people have the ability to learn in later life

Need to continue learning throughout life

There was some difference among the age groups in what was considered to be "the most important thing learned". A preponderance of the "preparation" responses were made by those who were in their forties or younger. Responses denoting "personal inspiration" were made most frequently by the older-age groups (50 and over).

Sixty-eight of the 96 students responded to the question, "What suggestions and criticisms do you have for the telecourse?" One-third complained that the 20-minute period was too short. Another third stated that they had no criticisms or suggestions. Among the suggestions offered were some which would be helpful to others developing similar telecourses. Some examples are : there should be a letter-box for students who wish to ask specific questions; there should be as many close-ups of material as possible; a visit to the studio should be scheduled for students who wish to see the class being televised; and a plan should be 
worked out so that individuals without TV sets could pool their resources to rent a set.

The following quotations of reasons given by the students for enrolling in the course and statements regarding what the course meant to them are perhaps the best evaluation of the usefulness of courses for and about the aging. Among the reasons given for enrolling were such statements as:

My children are growing up so fast, the thought of the empty years ahead made me decide to try to do something about it. (Age 38)

Seeing a grandma in the family without interests slowly dying of boredom-I don't want it to happen to me. (Age 30)

I am determined not to fall into the pattern set up by older relatives who either dominate their children's lives or act so touchy and unhappy that all my visits are merely duty calls. I want to be a "wanted" older woman. (Age 48)

Because at the age of $49 \mathrm{I}$ found my job opportunities were limited because of the prejudices of employers and group insurance companies and hence I must find a way of earning my way during the remaining years.

Because my wife, my mother, and I are very much interested in developing a plan for the "later years". (Age 46)

To get new ideas and suggestions to help my mother who is past 80 , with failing eyesight and in poor health, but miserable because she is so useless. (Age 50)

To determine whether I could still learn something. (Age 62)

To occupy leisure time. (Age 66the only student who was retired)

Examples of the outcomes of taking the course were reported as follows:

I signed up for a course in woodcraft at the local high school. (Age 41)

The TV class meeting pointed out to me the tremendous possibilities for older people to live an active and useful life. As a result, I am looking into the work of bookbinding. (Age 49)

The course presented the older person so favorably to my entire family. (Age 35)

I derived a lot of enjoyment out of the classes-but both my parents who are 65 learned a lot and it made them feel that life begins at 60 or 65. (Age 30)

An entirely different picture of retirement than I had before. I will not retire as planned. (Age 58)

A decision not to die at 50 and be buried at 77. (Age 57)

I have taken up making jewelry. (Age 45)

It was like returning to school though much more convenient. I enjoyed seeing real people in action. I was encouraged to look forward to a full college course for older people right in my own home. (Age 45)

Spurred to read about and investigate new hobbies for myself. (Age 42)

Life might begin at 40 , but it doesn't stop at 60. As a result of the course, I gave up the idea of retiring, decided to keep busy, and if something new presents itself by the way of a different kind of employment, I will not be afraid to launch out in a new line. (Age 60)

\section{Conclusion}

From the results of these various educational experiments several conclusions can be drawn. Older people can and want to learn. They will seek 
guidance with their problems of adjustment to aging through organized groups. Adults of all ages are developing an awareness of the need for educational experiences which will prepare them for a life of usefulness in their later years. The type of educational experience which is appropriate for older people is not limited to a static, classroom-lecture experience; learning appears to be even more highly motivated when active participation is provided. Edu- cation through the use of mass media is an effective means for instructing younger people about aging and the aged, and for motivating old people themselves. Educational agencies, through extension and correspondence services, community colleges, local adult education programs, and through existing community or work groups will, in all probability, be called upon to extend their programs to provide education and guidance in adjustment to aging.

\title{
The Program of the Fund for Adult Education
}

\author{
C. Scott Fletcher \\ President, Fund for Adult Education
}

"T THE EXPANSION of opportunities and improvement of methods for all citizens to continue education throughout adult life ..." was declared to be the aim of the Fund for Adult Education at the time it was established as an independent corporation by the Ford Foundation in April, 1951. The Fund was designed as one of two instrumentalities for attaining the goals of Area IV ${ }^{1}$ of the Ford
Foundation program, and the FAE marked off as its distinctive province "that part of the educational process which begins when formal schooling is finished". In addition to providing opportunities for adult education, it will try to cultivate in adults the desire to continue education throughout life.

Among the extensive list of activities which may be described as "adult education", the

1"The Ford Foundation will support activities to: strengthen, expand and improve educational facilities and methods to enable individuals more fully to realize their intellectual, civic, and spiritual potentialities; to promote greater equality of educational opportunity; and to conserve and increase knowledge and enrich our culture." Report of the Study for the Ford Foundation on Policy and Program, I, page 79. 